\title{
Molecular characterization of tumor necrosis $\alpha$-induced protein 6 and its human chorionic gonadotropin-dependent induction in theca and mural granulosa cells of equine preovulatory follicles
}

\author{
Khampoune Sayasith, Monique Doré ${ }^{1}$ and Jean Sirois \\ Québec, Canada J2S 7C6 \\ Correspondence should be addressed to K Sayasith; Email: k.sayasith@umontreal.ca
}

Centre de Recherche en Reproduction Animale and Département de Biomédecine Vétérinaire and ${ }^{1}$ Département de Pathologie et Microbiologie, Faculté de Médecine Vétérinaire, Université de Montréal, 3200 Sicotte, Saint-Hyacinthe,

\begin{abstract}
The preovulatory rise in gonadotropins causes an expansion of the cumulus-oocyte complex, a process requiring the induction of several genes. The objectives of this study were to clone the equine tumor necrosis factor $\alpha$-induced protein 6 (TNFAIP6), and investigate its regulation in equine follicles during human chorionic gonadotropin (hCG)-induced ovulation. The isolation of the equine TNFAIP6 cDNA revealed that it contains an open reading frame of $834 \mathrm{bp}$ (including the stop codon), encoding a predicted 277 amino acid protein that is highly similar (91-93\% identity) to known mammalian homologs. The regulation of TNFAIP6 mRNA was studied in equine follicles isolated during estrus between 0 and $39 \mathrm{~h}$ post-hCG and in corpora lutea (CL) obtained on day 8 of the estrous cycle. Results from semi-quantitative RT-PCR/Southern blot showed that levels of TNFAIP6 mRNA were low in follicles obtained at $0 \mathrm{~h}$, increased at $12 \mathrm{~h}$, returned to basal levels at $24 \mathrm{~h}$, and increased again at $36 \mathrm{~h}$ posthCG $(P<0.05)$. Levels of TNFAIP6 transcripts were relatively moderate in $\mathrm{CL}$, but low in non-ovarian tissues tested. Analyses performed with isolated preparations of theca and granulosa cells indicated that TNFAIP6 mRNA was regulated in both layers, with a maximal induction obtained 33-36 h post-hCG $(P<0.05)$. Immunohistochemical staining of sections of equine follicles isolated at 0 and $33 \mathrm{~h}$ post-hCG confirmed the induction of TNFAIP6 protein in both cell types after hCG treatment. Thus, the present study describes for the first time the gonadotropin-dependent regulation of follicular TNFAIP6 during the ovulation in a monoovulatory species. The biphasic induction of TNFAIP6 in equine theca and granulosa cells differs from the pattern observed in rodents, suggesting a distinct control of gene expression in this monoovulatory species.
\end{abstract}

Reproduction (2007) 133 135-145

\section{Introduction}

Tumor necrosis factor $\alpha$-induced protein 6 (TNFAIP6) belongs to the hyaladherin superfamily of hyaluronan (HA)-binding proteins (Wisniewski \& Vilcek 2004). It is composed of 277 amino acids that give rise to a secreted product of $35 \mathrm{kDa}$, and consists of the $\mathrm{N}$-terminal Link module and the C-terminal CUB domain. The Link module is known to interact with HA (Goetinck et al. 1987, Perin et al. 1987), whereas the CUB domain is found in a variety of proteins, many of which are involved in fertilization and development, but its precise physiological role remains unclear (Bork \& Beckmann 1993). Expression of TNFAIP6 is usually undetectable in normal adult tissues or non-stimulated cells but is rapidly induced during inflammatory diseases (Milner \& Day 2003). Indeed, high levels of TNFAIP6 have been detected in the synovial fluid of patients with rheumatoid arthritis or osteoarthritis (Bayliss et al. 2001), but not in healthy joint tissues (Wisniewski et al. 1993). In this context, TNFAIP6 has been shown to protect against cartilage matrix destruction and to exert anti-inflammatory activities by inhibiting the migration of polymorphonuclear cells into the inflamed site (Wisniewski et al. 1996, Getting et al. 2002, Glant et al. 2002, Mindrescu et al. 2002, Szanto et al. 2004).

Ovulation is a complex luteinizing hormone (LH)induced process that involves a series of biochemical and biophysical events. It is characterized by a marked formation of extracellular matrix (ECM) surround the cumulus cells that lead to the characteristic expansion of the cumulus-oocyte complex (COC; Salustri et al. 1999, Zhuo \& Kimata 2001). The highly viscoelastic ECM is composed predominantly of $\mathrm{HA}$ as well as other factors essential for matrix assembly, including proteoglycans, link protein, serum-derived factor inter $\alpha$-trypsin 
inhibitor (lal), and TNFAIP6 (Salustri et al. 1999, Zhuo \& Kimata 2001, Russell et al. 2003a). Expression of TNFAIP6 is increased in periantral mural granulosa and cumulus cells of mouse and rat preovulatory follicles after administration of an ovulatory dose of human chorionic gonadotropin (hCG; Fulop et al. 1997, Yoshioka et al. 2000). Owing to its ability to bind HA, it has been suggested that TNFAIP6 stabilizes the ECM (Fulop et al. 1997, Jessen \& Odum 2003). Indeed, TNFAIP6 and lal have been detected in the HA-rich matrix surrounding cumulus cells of the expanded mouse COC, and interactions of TNFAIP6 with $|\alpha|$ and $\mathrm{HA}$ at this levels have been reported (Wisniewski et al. 1996, Carrette et al. 2001, Mukhopadhyay et al. 2001). Furthermore, disruption of the TNFAIP6 gene resulted in impaired cumulus expansion and infertility in female mice (Fulop et al. 2003).

Preovulatory follicular development and ovulation in mares show several distinctive characteristics compared with rodents, such as a large diameter of the ovulatory follicle $(40-45 \mathrm{~mm})$, a relatively long ovulatory process (39-42 h), and the follicular rupture at a specific region of the ovary, the ovulatory fossa (Stabenfeldt et al. 1975, Duchamp et al. 1987, Ginther 1992, Sirois \& Doré 1997, Kerban et al. 1999). In contrast to rodents in which the expansion process appears primary limited to the COC, the preovulatory rise in gonadotropins in mares causes an extensive expansion of the entire mural granulosa cell layer characterized by an abundant accumulation of ECM (Kerban et al. 1999). The unique and remarkable cellular modifications observed in equine follicles prior to ovulation suggest that the regulation of TNFAIP6 may differ in this species. Moreover, all studies performed thus far on the regulation of TNFAIP6 in the ovary have been limited to rodents (Fulop et al. 1997, 2003, Yoshioka et al. 2000, Carrette et al. 2001, Mukhopadhyay et al. 2001), with no reports in primates and nonprimate monoovulatory species. Therefore, the specific objectives of this study were to clone and characterize the equine TNFAIP6 cDNA and to investigate its regulation in equine follicles during hCG-induced ovulation.

\section{Materials and Methods}

\section{Cloning of the equine TNFAIP6 CDNA}

The full-length equine TNFAIP6 cDNA was isolated by a combination of RT-PCR, and 5'- and 3'-RACE. RT-PCR was performed using sense and anti-sense primers (primers 1 and 2) designed from a highly conserved region identified after sequence alignments of human (GenBank accession number: NM_007115) and mouse (GenBank accession number: NM_009398) TNFAIP6 homologs, $100 \mathrm{ng}$ pooled equine ovarian RNA, and a OneStep RT-PCR System (Qiagen) as directed by the manufacturer (Fig. 1Aa). Pooled ovarian RNA consists of equal amounts of RNA prepared from a preovulatory follicle isolated before hCG, another follicle isolated $36 \mathrm{~h}$ after hCG, and a CL obtained on day 8 of the cycle (day 0, day of ovulation), as previously described (Boerboom et al. 2000). The RT-PCR product was subcloned into pGEM-T Easy vector (Promega), and sequenced (Service de Séquençage de Université de Laval, Québec, Canada). A large equine TNFAIP6 cDNA fragment was obtained and used to design the primers for $3^{\prime}$ - and $5^{\prime}$-RACE reactions.

To characterize the $3^{\prime}$-end of equine TNFAIP6 cDNA, a 3'-RACE was performed as previously described (Boerboom et al. 2000) using $5 \mu \mathrm{g}$ total RNA isolated from a preovulatory follicle obtained $36 \mathrm{~h}$ post-hCG. Briefly, RT was performed as directed by the manufacturer using SuperScript III RNase H-Reverse Transcriptase (Invitrogen Life Technologies) and a poly-dT oligonucleotide with anchor sequences at its $5^{\prime}$-end (primer 3) followed by a first PCR done with sense primer 4 and anti-sense 5, and a second nested-PCRs with sense primer 6 and anti-sense primer 7 (Fig. 1Ab). Primers 4 and 6 were designed from the 3 '-end of a large equine TNFAIP6 cDNA fragment.

To obtain the missing $5^{\prime}$-end of equine TNFAIP6 CDNA, the $5^{\prime}$-RACE system version 2.0 (Invitrogen Life Technologies) was used as directed by the manufacturer. RT was performed as directed using anti-sense primer 8 and $3 \mu \mathrm{g}$ RNA from $36 \mathrm{~h}$ post-hCG preovulatory follicle. The first 5'-RACE/PCR was performed with sense abridged anchor primer 9 (Invitrogen Life Technologies) and anti-sense primer 10, whereas the second $5^{\prime}$ RACE/PCR employed the sense abridged universal amplification primer 11 (Invitrogen Life Technologies) and anti-sense primer 12 (Fig. 1AC). The primers 8, 10, and 12 were designed from the $5^{\prime}$-end of large equine TNFAIP6 cDNA fragment. PCRs consisted of 35 cycles of $94{ }^{\circ} \mathrm{C}$ for $30 \mathrm{~s}, 58^{\circ} \mathrm{C}$ for $60 \mathrm{~s}$, and $72{ }^{\circ} \mathrm{C}$ for $1 \mathrm{~min}$. Final PCR products were subcloned into pGEM-T Easy vector and sequenced. The complete equine TNFAIP6 coding region was isolated by RT-PCR using 100 ng RNA from $36 \mathrm{~h}$ post-hCG preovulatory follicle, and sense primer 13 and anti-sense primer 14 (Fig.1Ad), subcloned into pcDNA $3.1(+)$ expression vector (Invitrogen Life Technologies), and sequenced. Primer sequences used are shown in Fig. 1B.

\section{Equine tissues and RNA extraction}

Equine preovulatory follicles and $\mathrm{CL}$ were isolated at specific stages of the estrous cycle from Standardbred and Thoroughbred mares as previously described (Kerban et al. 1999). Briefly, when preovulatory follicles reached $35 \mathrm{~mm}$ in diameter during estrus, the ovulatory process was induced by injection of hCG $(2500 \mathrm{IU}$, i.v. $)$ and ovariectomies were performed via colpotomy using an ovariotome at $0,12,24,30,33,36$, or 39 h post-hCG ( $n=4-6$ mares/time point). Corpora lutea ( $n=3$ mares) 
A

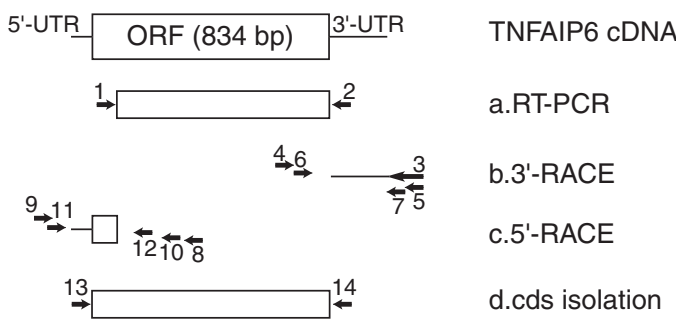

B

1. 5'-ATAACTCCATATGGCTTG-3'

2. 5'-TTATAAGATGGCTAAATCTTCCAG-3'

3. 5'-GTACCGGATCCTCTAGAGAGCTCGTGGACCTCG AGGAATTCAAGCTTTTTTTTTTTTTTTT-3'

4. 5'-TTCTAAGCGATGCTTCGGTGACCG3'

5. 5'-GTGGACCTCGAGGAATTCAAGCTT-3'

6. 5'-AATCTAAGTACGTGGCAGTGGATCC-3'

7. 5'-GTACCGGATCCTCTAGAGAGCTC-3'

8. 5'-TAATCAATAATACCAGTTT-3'

9. 5'-GGCCACGCGTCGACTAGTACGGGGGGGGGG-3'

10. 5'-TATCCAACTCTACCCTTGGCC-3'

11. 5'-CTACTACTACTATAGGCCACGCGTCGACTAGTAC-3'

12. 5'-CGCTTCTGCGTAGGTGAGCTTG-3'

13. 5'-GTGGAATTCGCCGCCACCATGGTCATCTTAATTTA CTTATTTGTCC-3'

14. 5'-ACCTCTAGATCGTTATAAATGGCTAAATCTTCCAGC-3'

Figure 1 Cloning strategy for isolating the equine TNFAIP6 CDNA. (A) The open reading frame (ORF) of equine TNFAIP6 is represented as an open box whereas the $5^{\prime}$ - and $3^{\prime}$-UTR are shown as solid lines; the numbers in parenthesis indicate the size in base pairs of equine TNFAIP6 ORF. The equine TNFAIP6 cDNA was characterized by a combination of RT-PCR (a), 3'-RACE (b) and 5'-RACE (c), as described in Materials and Methods, and the complete equine TNFAIP6 coding sequence was isolated by RT-PCR; arrows and numbers refer to the orientation, relative position and identity of oligonucleotide primers used in each cloning procedure. (B) List of primers used in section A for equine TNFAIP6 cloning. The abridged anchor primer (9) and abridged universal amplification primer (11) are components of the $5^{\prime}$-RACE system.

were isolated on day 8 of the estrus cycle. Preovulatory follicles and CL were dissected from the surrounding ovarian tissues with a scalpel. Follicles were dissected into three cellular preparations referred to as the follicular wall (theca interna with attached granulosa cells), and isolated granulosa cells and thecal layers, as described (Sirois et al. 1991). The relative purity of each cellular preparation is estimated to exceed $95 \%$ based on the selective expression of P450 17 $\alpha$-hydroxylaseC17-20 lyase (CYP17A1) and P450 aromatase (CYP19A1) mRNAs by theca interna and granulosa cells respectively (Boerboom et al. 1999). Testicular tissues were obtained from the Large Animal Hospital of the Faculté de médecine vétérinaire (Université de Montréal) following a routine castration, whereas other non-ovarian tissues were collected at a local slaughterhouse. The institutional animal use and care committee approved all animal procedures. Total RNA was isolated from tissues with TRIzol reagent (Invitrogen), according to manufacturer's instructions using a Kinematica PT 1200C Polytron Homogenizer (Fisher Scientific, Montréal, Canada).

\section{Semi-quantitative RT-PCR and Southern blot analysis}

The semi-quantitative analysis of TNFAIP6 and rpL7a mRNA levels in equine tissues was performed using a OneStep RT-PCR System as directed by the manufacturer (Qiagen), and sense (5'-TAC AAG CAG CTA GAG GCA GCC $\left.-3^{\prime}\right)$ and anti-sense ( $5^{\prime}$-CTT CAA GGT CAT GAC ATT TCC TG-3') primers specific for equine TNFAIP6 (generating a DNA fragment of $483 \mathrm{bp}$ ), and sense (5'ACA GGA CAT CCA GCC CAA ACG-3') and anti-sense (5'-GCT CCT TTG TCT TCC GAG TTG-3') primers specific for equine rpL7a (generating a DNA fragment of $516 \mathrm{bp}$ ). The equine rpL7a primers were designed from a published sequence (GenBank accession number: AF508309) and its transcript expression has been shown to be relatively constant during the equine ovulatory process (Brown et al. 2004, Sayasith et al. 2005). Each reaction was conducted using $100 \mathrm{ng}$ total $\mathrm{RNA}$, and cycling conditions were one cycle of $50^{\circ} \mathrm{C}$ for $30 \mathrm{~min}$ and $95^{\circ} \mathrm{C}$ for $15 \mathrm{~min}$, followed by a 17 (for TNFAIP6) or 18 (for rpL7a) PCR cycles of $94{ }^{\circ} \mathrm{C}$ for $30 \mathrm{~s}$, $58{ }^{\circ} \mathrm{C}$ for $1 \mathrm{~min}$, and $72{ }^{\circ} \mathrm{C}$ for $2 \mathrm{~min}$. The number of PCR cycles used was determined by running a RT-PCR in $50 \mu \mathrm{l}$. A volume of $5 \mu \mathrm{l}$ was pipetted after each three PCR cycles, starting from the end of the twelfth cycle of amplification. PCR products were electrophoresed on $2 \%$ Tris-acetic acid EDTA (TAE)-agarose gels, transferred to biotrans nylon membranes (ICN Pharmaceuticals, Montréal, Québec), and hybridized with corresponding radiolabeled TNFAIP6 and rpL7a cDNA fragments using QuikHyb hybridization solution (Stratagene, LaJolla, CA, USA). Membranes were exposed to a phosphor screen. Signals were quantified on a Storm imaging system using the ImageQuant software version 1.1 (Molecular Dynamics, Amersham Biosciences), and used to establish a standard curve of amplification in which the number of PCR cycles falling in linear range of amplification corresponding to optimal reactions (exponential amplification) was determined.

\section{Cell cultures, transient transfection, and immuno- blotting analysis}

To validate the specificity of the antibody used against equine TNFAIP6, equine granulosa cell line was assessed in our laboratory (unpublished results) and cultured in Dulbecco's modified Eagle's medium (DMEM)-F12 (Invitrogen Life Technologies) containing L-glutamine, non-essential amino acids, $10 \%$ fetal bovine serum, and penicillin (100 units $/ \mathrm{ml})$ and streptomycin $(100 \mu \mathrm{g} / \mathrm{ml})$. Cultures were maintained at $37^{\circ} \mathrm{C}$ 
in a humidified atmosphere of $5 \% \mathrm{CO}_{2}$, and transiently transfected with $4 \mu \mathrm{g} /$ petris TNFAIP6 expression vector using $30 \mu \mathrm{g}$ LipofectAMINE PLUS reagent in $4 \mathrm{ml}$ DMEM-F12, in accordance with manufacturer's protocol (Invitrogen Life Technologies). Three hours after transfection, cells were rinsed and incubated in culture media for $24 \mathrm{~h}$. After incubation, culture medium and cells were harvested, and the whole cell protein extraction was performed as previously described (Sayasith et al. 2004). Protein concentrations were determined by the method of Bradford (1976; Bio-Rad Protein Assay). Samples (100 $\mu$ g) were analyzed by onedimensional SDS-PAGE $(10 \%)$ and electrophoretically transferred to PVDF membranes. Membranes were incubated with anti-human TNFAIP6 polyclonal antibody (1:100 dilution; Santa Cruz Biotechnologies, Santa Cruz, CA, USA), anti-human TNFAIP6 polyclonal antibody $(2 \mu \mathrm{g} / \mathrm{ml}$; R\&D Systems), or anti-mouse TNFAIP6 polyclonal antibody $(2 \mu \mathrm{g} / \mathrm{ml}$; R\&D Systems), and immunoreactive proteins were visualized by incubation with the horseradish peroxidase-linked donkey anti-goat secondary antibody (1:5000 dilution) and the ECL detection system (Western Blotting Luminol Reagent) according to manufacturer's protocol (Santa Cruz Biotechnologies). In parallel, the follicular fluid isolated from equine preovulatory follicle after $36 \mathrm{~h}$ post-hCG was also assayed.

\section{Immunohistochemical localization of TNFAIP6 in equine follicles}

Immunohistochemical staining was performed using the Vectastain ABC kit (Vector Laboratories, Burlingame, CA, USA), as previously described (Sirois \& Doré 1997). Briefly, formalin-fixed tissues were paraffin embedded and $3 \mu \mathrm{m}$ thick sections were prepared and then the paraffin was removed using a series of alcohol concentrations. Endogenous peroxidase was quenched by incubating the slides in $0.3 \%$ hydrogen peroxide in methanol for $30 \mathrm{~min}$. After rinsing in PBS for $15 \mathrm{~min}$, sections were incubated with diluted normal goat serum for $20 \mathrm{~min}$ at room temperature. The anti-human TNFAIP6 antibody (Santa Cruz Biotechnologies) was diluted in PBS (1:25) and applied, and sections were incubated overnight at $4{ }^{\circ} \mathrm{C}$. Control sections were incubated with PBS. After rinsing in PBS for $10 \mathrm{~min}$, a biotinylated goat anti-rabbit antibody (1:222; Vector Laboratories) was applied, and sections were incubated for $45 \mathrm{~min}$ at room temperature. After washing in PBS for $10 \mathrm{~min}$, sections were incubated with the avidin $\mathrm{DH}$-biotinylated horseradish peroxidase $\mathrm{H}$ reagents for $45 \mathrm{~min}$ at room temperature, washed with PBS for $10 \mathrm{~min}$, and incubated with diaminobenzidine tetrahydrochloride (Sigma) as the chromogen substrate. Sections were counterstained with Gill's hematoxylin stain and mounted.

\section{Statistical analysis}

One-way ANOVA was used to test the effect of time after hCG on levels of TNFAIP6 mRNA in samples of theca and granulosa cells. TNFAIP6 mRNA levels were normalized with the control gene rpL7a prior to analysis. When ANOVA indicated significant differences $(P<0.05)$, the Dunnett's test was used for multiple comparisons of individual means. Statistical analyses were performed using JMP software (SAS Institute, Inc., Carry, NC, USA).

\section{Results}

\section{Characterization of the equine TNFAIP6 CDNA}

To clone equine TNFAIP6 cDNA, an equine TNFAIP6 cDNA fragment of 760 bp was first isolated by RT-PCR using primers designed by sequence alignments of human and mouse TNFAIP6 homologs (Fig. 1Aa). Sense and anti-sense primers designed from the latter cDNA fragment were used in $3^{\prime}$ - and $5^{\prime}$-RACE reactions to characterize the $3^{\prime}$-end and to obtain the missing $5^{\prime}$ end of equine TNFAIP6 cDNA (fragments of 275 and $159 \mathrm{bp}$ respectively; Fig. $1 \mathrm{~A} b$ and $A c)$. Results showed that the equine TNFAIP6 cDNA is composed of a $5^{\prime}$-UTR of $85 \mathrm{bp}$, an open reading frame of $834 \mathrm{bp}$ (including the stop codon), and a 3'-UTR of $209 \mathrm{bp}$ (Fig. 2A). The nucleotide sequence was submitted to GenBank with accession number AY919871.

The predicted complete coding region of equine TNFAIP6 was isolated by RT-PCR, subcloned, and confirmed by sequencing. This region encodes a 277 amino acid protein, which is similar in length with human (GenBank accession number: NM_007115), three amino acids shorter than bovine (GenBank accession number: NM_001007813), and two amino acids longer than mouse (GenBank accession number: NM_009398) TNFAIP6 (Fig. 2B). Comparative analyses revealed that the equine TNFAIP6 sequence is highly similar to its homologs, with a $91 \%$ (human and bovine) and $85 \%$ (mouse) identity observed at the nucleic acid level, and a 91\% (human), 93\% (bovine), and 90\% (mouse) identity at the amino acid level (Fig. 2B). Moreover, structural domains putatively involved in TNFAIP6 function are conserved in the equine protein, including a Link module and a CUB domain (Fig. 2B).

\section{Tissue distribution of equine TNFAIP6 $\mathrm{mRNA}$ and its regulation in mural granulosa and theca cells of preovulatory follicles and in $C L$}

The relative expression of TNFAIP6 mRNA in various equine tissues was studied by RT-PCR/Southern blot. Results showed that levels of TNFAIP6 transcripts were highly detected in preovulatory follicle isolated $12 \mathrm{~h}$ after hCG, low in heart, brain, lung, adrenal gland, and uterus, and very low or undetectable in other tissues 
ggggggtgagtcacatttcagcctc tgctctgagaatttatcctgagcag 50 cCcctaacaggetgttacttctcta caactgagctATGATCATCTTAATT 100 TACGTACTTGTCTTGCTGTGGGAAG AGGCTCACGGATGGGGATTCAAGAA 150 TGGAATTTTTCATAACTCCATATGG CTTGAACAAGCAGCAGGAGTATACC 200 ACAGAGAAGCACGGTCTGGAAAATA CAAGCTCACCTACGCAGAAGCGAAG 250 GCGGTGTGTGAATACGAAGGTGGCC ATCTCGCCACCTATAAGCAGCTAGA 300 AGCAGCCAGAAAAATTGGATTTCAC GTCTGTGCTGCTGGGTGGATGGCCA 350 AGGGTAGAGTTGGATACCCCATTGT GAAGCCAGGGCCCAACTGTGGTTTT 400 GGAAAAACTGGTATTATTGATTACG GAATCCGTCTCAACAGGAGTGAAAG 450 ATGGGATGCCTACTGCTACAACCCA CATGCAAAGGAATGCGGTGGCATCT 500 TTACAGATACAAAGAGAATTTTTAA ATCTCCAGGCTTCCCAAATGAATAT 550 GATGATAACCAAGTCTGCTACTGGC ACATCAGACTCAAGTATGGTCAGCG 600 TATTCACCTGAGTTTTCTGGACTTT GATCTTGAAGACGATACAGGTTGCT 650 TGGCTGACTATGTTGAAATATATGA CAGTTATGATGATGTCCATGGCTTT 700 GTGGGAAGATACTGTGGAGATGAGC TTCCAGAAGACATCATTAGCACAGG 750 AAATGTCATGACTTTGAAGTTTCTA AGCGATGCTTCGGTGACCGCAGGAG 800 GTTTCCAAATCAAGTACGTGGCAGT GGATCCCCCATCCAAACCCAGTCAA 850 GGAAAAAATACAAGCACTACTTCTA CGGGAAATAAAAGCTTTTTAGCTCC 900 AAGTTTTACCCATTTATAAaacaaa aaaaggacattcagtgtttatggtt 950 gtctctttggaaccctttgatct cagttttgtattattattaacattt 1000 atttattattttgtaaatgtgaaa accatacctgataatttggggaaaa 1050 ttggaaaatacagtaaactttaaat gagaaaaataaatctcttataatt 1100 catctgcataaaaaaaaaaaaaa aa 1127

B

Equ MIILIYVLVLLWEEAHGWĞFKNGIFHNS IWLEQAAGVYHREARSGKYKLT 50

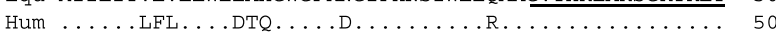

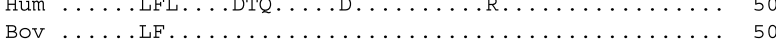
Mou .VV.LCLC . . . . . . . . . . . . . . . . . . 50

Equ YAEAKAVCEYEGGHLATYKQLEAARKIGFHVCAAGWMAKGRVGYPIVKPG 100

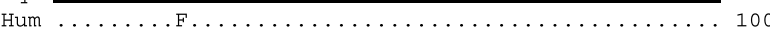

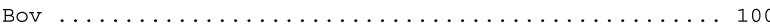
Mou ......F..R..................... 100

Equ PNCGFGKTGIIDYGIRL $\overline{\overline{\text { RRS }}}$ ERWDAYCYNPHAKE $\overline{\overline{C G G I F T D T K R I F K S P G ~}} 150$

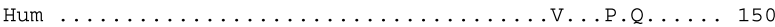
Bov ................................ 150

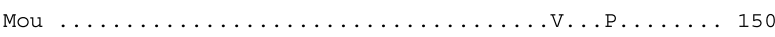
Equ $\overline{\text { FPNEYDDNQVCYWHIRLKYGQRIHLSFLDFDLEDDTGCLADYVEIYDSYD }} 200$

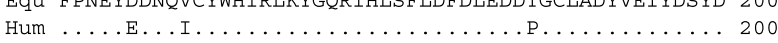
Bov $\ldots \ldots \ldots$ I. ...................... 200

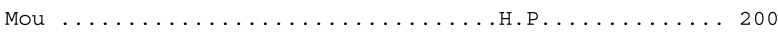

Equ DVHGFVGRYCGDELPEDIISTGNVMTLKFLSDASVTAGGFQIKYVAVDPP 250

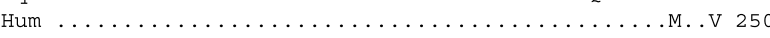

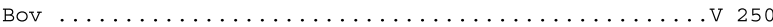

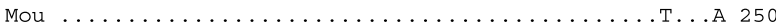

Equ SKPSQGK---NTSTTSTGNKSFLAPSFTHL 277 (100\%)

Hum ..................GR.S. . 277 (91\%)

BOV ..S. . NAST . . . . . . . .GR.S.. 280 (93\%)

Mou ..S.A.N----TST. ...K..PGR.S. . 275 (90\%)

Figure 2 Nucleotide sequence of equine TNFAIP6 and comparisons of its deduced amino acid sequence with other mammalian homologs. (A) The equine TNFAIP6 CDNA was cloned by a combination of RT-PCR and 5'and $3^{\prime}-$ RACE, as described in Materials and Methods, and is composed of a $5^{\prime}$-UTR of 85 bp (lowercase letters), an ORF of 834 bp (uppercase letters), and a 3'-UTR of $209 \mathrm{bp}$ (lowercase letters). The translation initiation (ATG) and stop (TAA) codons are bolded and numbers on the right refer to the last nucleotide on that line. Overlapped Shaw-Kamen motifs are underlined and a consensus polyadenylation signal sequence is double underlined. The nucleotide sequence was submitted to GenBank with accession number AY919871. (B) The amino acid sequence of equine (equ) TNFAIP6 is aligned with the human (hum), bovine (bov), and mouse (mou) homologs. Identical residues are noted with a printed period, hyphens indicate gaps in protein sequences created to optimize alignment, the numbers on the right are for the last amino acid residue on that line, and the percentage in parentheses refers to the percentage of identity in amino acid residues when comparisons are made with equine TNFAIP6. The putative HA-binding domain, referred to as the Link module, is underlined; and the domain referred to as the CUB domain, is overlined. Asparagine $(N)$-linked glycosylation consensus sequences are double overlined. Signal peptide cleavage site is marked with an arrowhead. tested (Fig. 3A). In contrast, the levels of rpL7a mRNA (control gene) remained relatively constant in these tissues (Fig. 3B).

The regulation of TNFAIP6 mRNA during the ovulatory process was studied by semi-quantitative RT-PCR/Southern blot using total RNA extracted from follicle walls (theca interna layer with attached

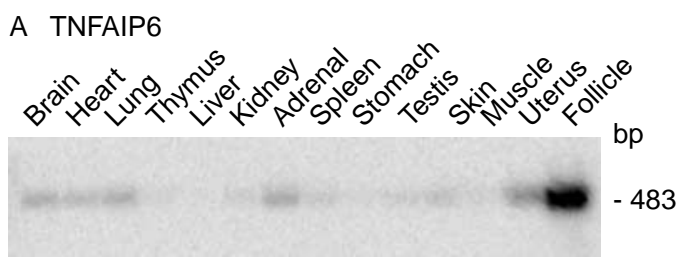

B rpL7A

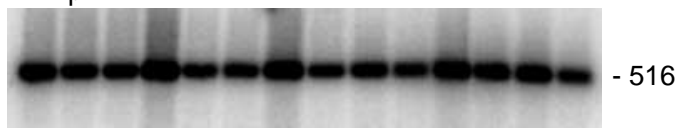

C
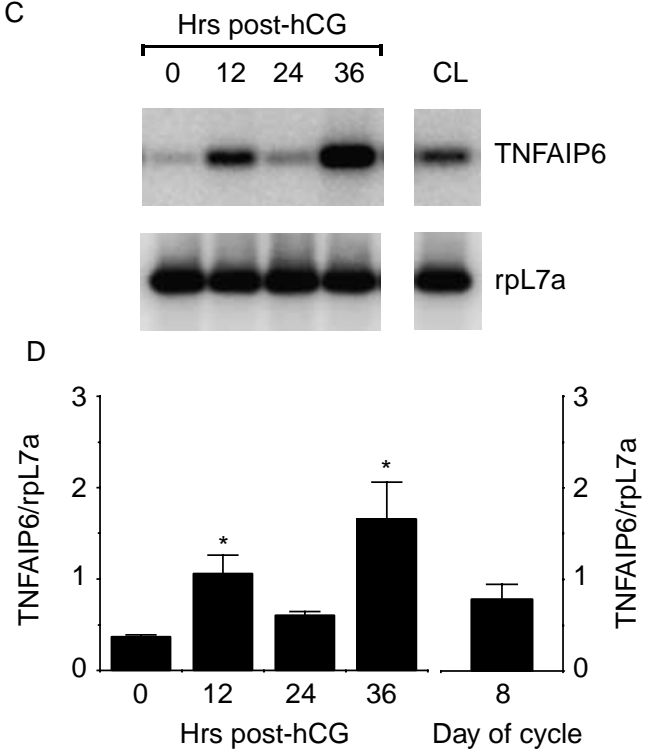

Figure 3 Equine tissue expression of TNFAIP6 mRNA and its gonadotropin-dependent regulation in preovulatory follicles. Relative expression of equine TNFAIP6 (A) and rpL7a (control gene; B) were analyzed by a semi-quantitative RT-PCR/Southern blot, as described in Materials and Methods, using total RNA (100 ng) extracted from various equine tissues. The number of PCR cycles for both genes was 18 cycles and was optimized to fall within the linear range of the PCR amplification. Numbers on the right indicate the size of the PCR fragment. (C and D) RNA extracts were prepared from equine preovulatory follicles at $0,12,24$, and $36 \mathrm{~h}$ after administration of an ovulatory dose of human chorionic gonadotropin (hCG) and corpora lutea $(\mathrm{CL})$ were isolated on day 8 of the cycle. Samples $(100 \mathrm{ng})$ were analyzed by a semi-quantitative RT-PCR/Southern blot for the expression of TNFAIP6 and rpL7a transcripts, as described in Materials and Methods. Representative results of TNFAIP6 and rpL7a mRNA levels are presented from one follicle/time point (C). The TNFAIP6 signal was normalized with the control gene $\mathrm{rpL} 7 \mathrm{a}$, and results are presented as ratios of TNFAIP6 to rpL7a (D). Mean \pm S.E.M.; $n=4-6$ distinct follicles or $n=3 \mathrm{CL}$ (i.e. mares) per time point. Bars marked with an asterisk are significantly different from $0 \mathrm{~h}$ post-hCG $(P<0.05)$. 
granulosa cells) of equine preovulatory follicles isolated between 0 and $36 \mathrm{~h}$ after hCG treatment, and $\mathrm{CL}$ obtained on day 8 of cycle. Representative results indicated that TNFAIP6 mRNA expression was low before the hCG treatment $(0 \mathrm{~h})$, moderate at $12 \mathrm{~h}$, low at $24 \mathrm{~h}$, and high at $36 \mathrm{~h}$ post-hCG (Fig. 3C). Levels of TNFAIP6 transcripts were relatively moderate in $\mathrm{CL}$ (Fig. 3C). When results from several follicles $(n=4-6$ (e.g. each from different animal)) and $\mathrm{CL}(n=3)$ were expressed as ratios of TNFAIP6 to rpL7a, a significant biphasic pattern of the TNFAIP6 mRNA induction was observed in preovulatory follicles, with an increase in levels of TNFAIP6 transcript at 12 and $36 \mathrm{~h}$ post-hCG as compared with $0 \mathrm{~h}(P<0.05 ;$ Fig. 3D). Treatment with an ovulatory dose of gonadotropin did not affect rpL7a mRNA expression in preparations of follicle wall and CL at any time point tested.

\section{Localization of equine TNFAIP6 in preovulatory follicles}

To determine the cellular localization of equine TNFAIP6 mRNA expression in preovulatory follicles, RT-PCR/Southern blot was performed using isolated preparations of mural granulosa cells and theca layers obtained from equine preovulatory follicles collected 0-39 h after hCG treatment. Results showed that the TNFAIP6 transcript occurred in a biphasic manner in both cellular preparations, with a predominant expression of TNFAIP6 mRNA in theca layers. In mural granulosa cells, TNFAIP6 mRNA expression was low at 0 , increased at $12 \mathrm{~h}$, returned to basal levels at 24 and $30 \mathrm{~h}$, and increased again between 33 and $39 \mathrm{~h}$ posthCG (Fig. 4A). When results from several follicles $(n=$ 4-6) were expressed as ratios of TNFAIP6 to rpL7a, an significant increase in TNFAIP6 mRNA expression was observed at 12, 33, 36, and $39 \mathrm{~h}$ post-hCG, as compared with $0 \mathrm{~h}(P<0.05$; Fig. 4B). In theca layers, expression of the equine TNFAIP6 transcript was low at $0 \mathrm{~h}$, increased at $12 \mathrm{~h}$, returned to low levels at $24 \mathrm{~h}$, and increased again between 30 and $39 \mathrm{~h}$ post-hCG (Fig. 4C). Results from multiple follicles $(n=4-6)$ expressed as ratios of TNFAIP6 to rpL7a revealed an increase in TNFAIP6 mRNA levels at $12 \mathrm{~h}$, and between 30 and $39 \mathrm{~h}$ posthCG, as compared with $0 \mathrm{~h}(P<0.05$; Fig. 4D).

To determine if the induction of the TNFAIP6 mRNA was associated with the expression of its protein, immunohistochemistry was performed on sections of equine preovulatory follicles isolated before and after hCG. As anti-equine TNFAIP6 antibody is not available commercially, an anti-mouse TNFAIP6 polyclonal antibody obtained from R\&D Systems (Fig. 5A) and two anti-human TNFAIP6 polyclonal antibodies obtained from R\&D Systems (Fig. 5B) and Santa Cruz Biotechnologies (Fig. 5C) were primarily tested for their specificity against equine TNFAIP6 protein by immunoblotting using the follicular fluid isolated from preovulatory follicle after $36 \mathrm{~h}$ post-hCG (lane 1) and the culture medium (lane 2) and protein extracts (lane 3) isolated from granulosa cells overexpressing equine TNFAIP6. Results revealed that multiple protein bands were recognized by the antibodies in follicular fluid and culture medium (Fig. 5, lanes 1 and 2), situation also observed in other studies (Rugg et al. 2005, Sanggaard et al. 2005): the lower band appears in the range of $38 \mathrm{kDa}$ (a) corresponding to the monomer of full-length TNFAIP6 protein in the absence of post-translational modifications; the band indicated by $c$ letter most likely corresponds to dimeric form of TNFAIP6; the protein bands (b) between monomeric and dimeric forms may represent the TNFAIP6 proteins with different extents of glycosylation, as suggested previously (Wisniewski et al.
A

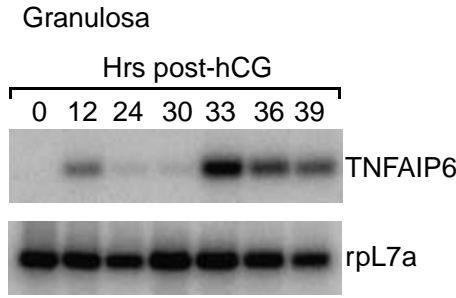

B

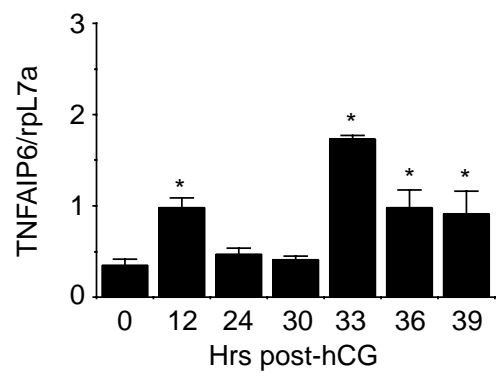

C

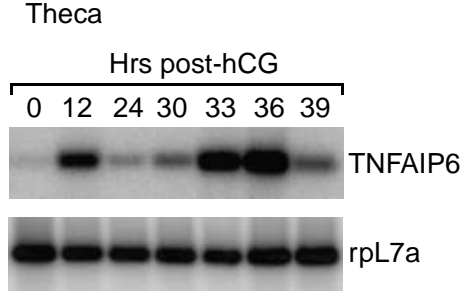

D

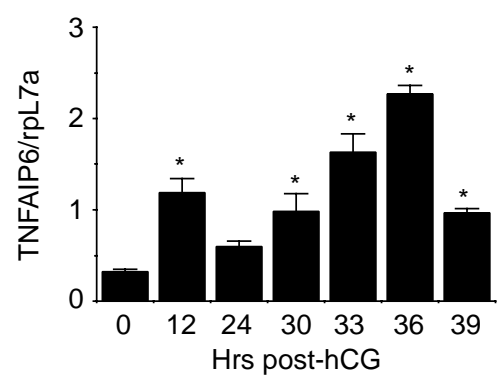

Figure 4 Cellular localization of TNFAIP6 mRNA in equine preovulatory follicles. Total RNA was separately extracted from granulosa and theca cells isolated from equine preovulatory follicles between 0 and $39 \mathrm{~h}$ posthCG, and samples (100 ng) were analyzed for TNFAIP6 and rpL7a content by a semiquantitative RT-PCR/Southern blot, as described in Materials and Methods. Representative results of TNFAIP6 and rpL7a mRNA levels are presented from one granulosa $(\mathrm{A})$ and one theca $(\mathrm{C})$ sample per time point. (B and D) The TNFAIP6 signal was normalized with the control gene rpL7a, and results are presented as ratios of TNFAIP6 to rpL7a (mean \pm s.E.M.; $n=4-5$ samples (i.e. mares) per time point). Bars marked with an asterisk are significantly different from $0 \mathrm{~h}$ post-hCG $(P<0.05)$. 


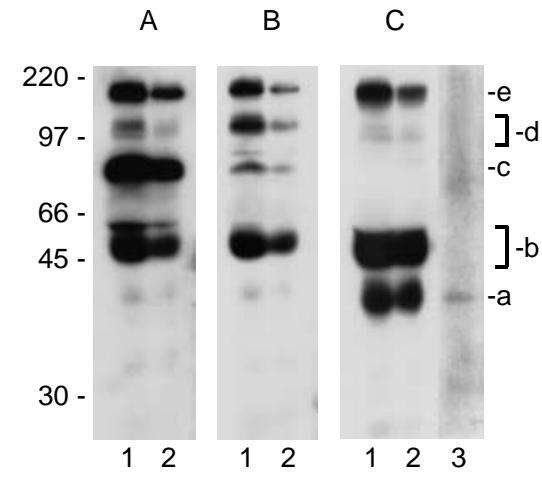

Figure 5 Validation of the antibody specificity against equine TNFAIP6 protein. The follicular fluid isolated from preovulatory follicle after $36 \mathrm{~h}$ post-hCG (lane 1) and the culture medium (lane 2) or protein extracts isolated from granulosa cells overexpressing equine TNFAIP6 (lane 3) were analyzed by one-dimensional SDS-PAGE and immunoblotting using anti-mouse TNFAIP6 polyclonal antibody (A) and anti-human TNFAIP6 polyclonal antibody (B) obtained from R\&D systems, and anti-human TNFAIP6 polyclonal antibody obtained from Santa Cruz Biotechnologies (C), as described in Materials and Methods. Markers on the left indicate the migration of molecular weight standards. Protein bands indicate multiple forms of TNFAIP6 in the absence or presence of the complexes: the lower band appears in the range of $38 \mathrm{kDa}$ (a) corresponding to the monomer of TNFAIP6 protein; the band indicated by c letter most likely represents a dimeric form of TNFAIP6; the protein bands marked by b letter may correspond to TNFAIP6 proteins with different extents of glycosylation; the bands noted by $d$ letter most likely correspond to the complexes of TNFAIP6 and heavy chains (HC1 and HC2) of I $|\alpha|$; and the upper band (e) may represent a TNFAIP6.Ial complex.

1994, Sanggaard et al. 2005); the bands noted by $d$ letter most likely correspond to the complexes of TNFAIP6 and heavy chains ( $\mathrm{HC} 1$ and $\mathrm{HC} 2$ ) of $|\alpha|$; and the upper band (e) may corresponds to a TNFAIP6.I $\alpha$ l complex. Interestingly, antibodies originated from different suppliers or species recognize the same protein bands with different extents in similar samples (Fig. 5, lanes 1 and 2). Moreover, a single band of TNFAIP6 (a) was observed in protein extracts prepared from granulosa cells overexpressing equine TNFAIP6 (Fig. 5, lane 3), whereas, no band was detected with a mock transfection (data not shown). In any cases, further studies will be needed to establish the exact identity of TNFAIP6-binding proteins.

Using anti-human TNFAIP6 polyclonal antibody (Santa Cruz Biotechnologies), immunohistochemical analyses revealed an increase in equine TNFAIP6 staining in preovulatory follicles after hCG treatment. Indeed, TNFAIP6 immunochemical staining was low in follicles with a very compact granulosa cell layer obtained before hCG treatment (0 h; Fig. 6A), but highly increased in mural granulosa cells and theca layer of preovulatory follicles obtained at 12,33 , and $36 \mathrm{~h}$ posthCG (Fig. 6B-E). This increase is accompanied by a progressive loosening (i.e. expansion) of the granulosa cell layer induced by $\mathrm{hCG}$, and the presence of TNFAIP6 protein in the cytoplasm of granulosa cells as well as outside (arrows) of these cells, in keeping with the high levels of TNFAIP6 mRNA detected during these times. As control of a staining, the primary antibody was replaced with PBS, and no staining was observed (33 h; Fig. 6F).

\section{Discussion}

The aim of this report was to study the regulation of TNFAIP6 in theca and mural granulosa cells of equine preovulatory follicles during the ovulatory process induced by hCG (ovulation occurs around $42 \mathrm{~h}$ posthCG in this species). TNFAIP6 has been shown to play important roles for completion of COC expansion during ovulation, since targeted disruption of the TNFAIP6 gene caused a defect in the COC expansion and infertility in female mice (Fulop et al. 2003). Studies on the regulation of TNFAIP6 in the ovarian physiology have been limited to rodents, with no report on its expression in large monoovulatory species, including mares. In contrast to other species, the preovulatory rise of $\mathrm{LH}$ in mares induces a unique and remarkable expansion associated with extensive synthesis and assembly of a viscoelastic ECM within the granulosa cell layer in follicles prior to ovulation (Kerban et al. 1999). Previous studies have shown that the spatial and temporal regulation of several genes involved in steroidogenesis and ovulation in equine preovulatory follicles is also different from that observed in the rodent ovary (Boerboom et al. 1999, 2000, 2003). Therefore, the present study identified other key differences. Indeed, the gonadotropin-dependent induction of TNFAIP6 in equine preovulatory follicles was prolonged and biphasic, differing with its rapid and monophasic induction in rodents (Yoshioka et al. 2000). The biphasic induction of equine TNFAIP6 clearly occurred in both mural granulosa and theca cells, and was not limited to granulosa cells as observed in rodents (Fulop et al. 1997, 2003, Yoshioka et al. 2000, Carrette et al. 2001, Mukhopadhyay et al. 2001). These findings further identify marked differences in the pattern of ovarian gene expression across species, and underscore value of using different animal models.

The viscoelastic ECM is thought to play multiple roles in ovulation and fertilization, including its capacity to keep the cumulus cells together with the oocyte; extrusion of the detached complex from the follicle during ovulation; facilitating its capture by, and transport in the oviduct; and as a physical barrier for the selection of highly functional and motile spermatozoa (Mahi-Brown \& Yanagimachi 1983, Neuwinger et al. 1991, Aitken et al. 1992, Salustri et al. 1999). Our study establishes that the ECM of equine follicles contains TNFAIP6. As demonstrated with other species, the ECM of an expanded COC contains, at least, HA, proteoglycans, |al, and TNFAIP6 (Chen et al. 1992, Salustri et al. 1999, Russell et al. 2003a, 2003b). Moreover, the co-localization of TNFAIP6, $|\alpha|$, and HA in the ECM of 

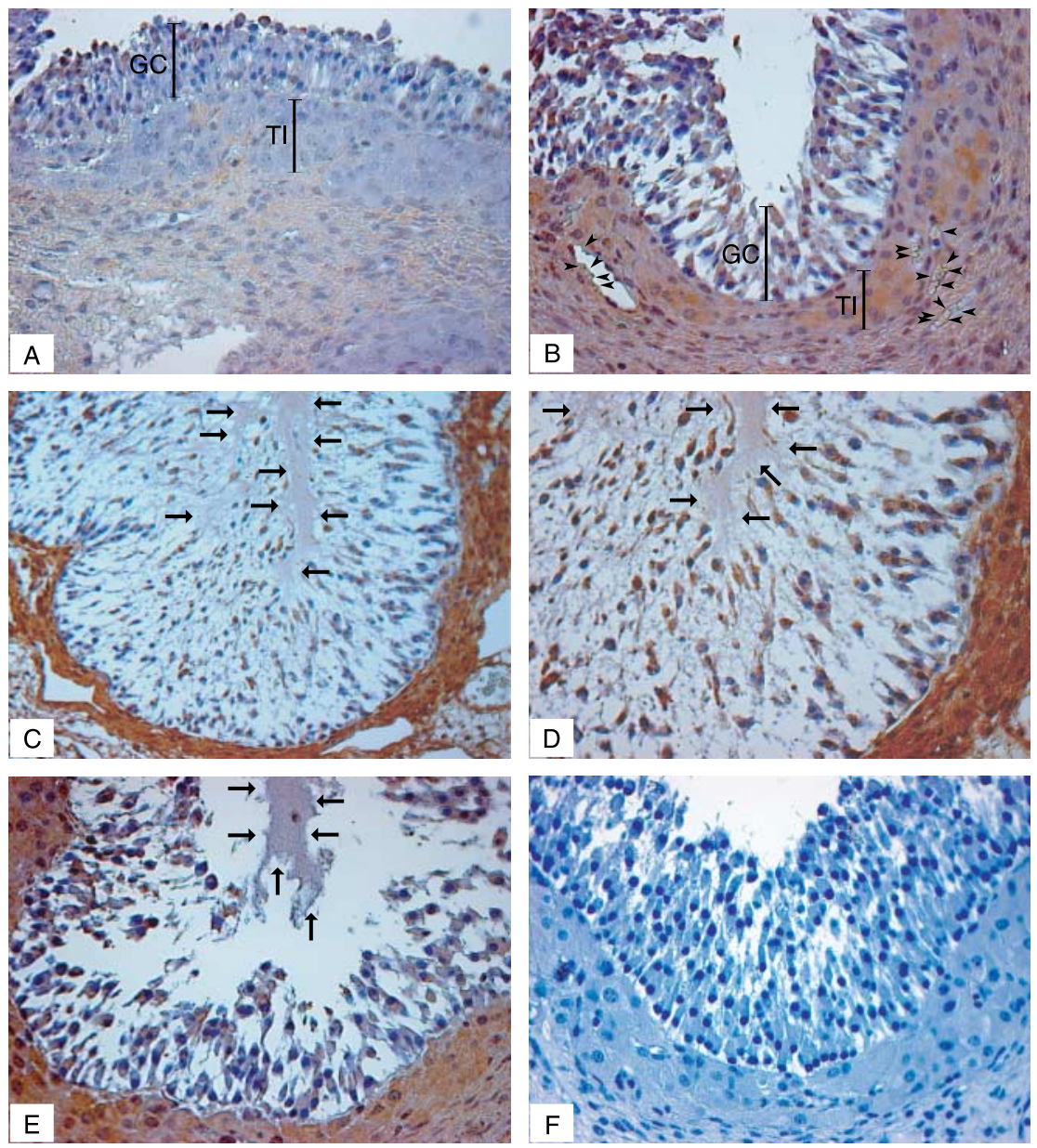

Figure 6 Immunohistochemical localization of TNFAIP6 protein in equine preovulatory follicles. Immunohistochemistry was performed on formalin-fixed sections of preovulatory follicles isolated before and after hCG, as described in Materials and Methods. Results show low TNFAIP6 staining in follicles obtained at $0 \mathrm{~h}(\mathrm{~A})$, but a marked immunoreactivity (staining) was detected in mural granulosa and theca cells of follicles isolated 12 (B), 33 (C and $\mathrm{D})$, and $36 \mathrm{~h}$ (E) post-hCG, in keeping with high levels of TNFAIP6 mRNA detected at these times. (F) Control staining from the follicular tissue presented in $\mathrm{C}$ and $\mathrm{D}$ was negative when the primary antibody was replaced with PBS. The limits of the mural granulosa cell (GC) layer and theca interna $(\mathrm{TI})$ are indicated ( $\mathrm{A}$ and $\mathrm{B})$. The region above the granulosa cell layer is for the antrum, whereas the region immediately beneath corresponds to thecal layers, including the limits of TI. TNFAIP6 protein is present in the cytoplasm of granulosa cells as well as secreted outside of cells (C-E; arrows). Arrowheads indicate vascular structures with circulation cells (B). Magnification, A, B, and D-F ( $X$ $400)$, and $C(\times 200)$. murine COC has been established, and evidence showed that TNFAIP6 can covalently link to the heavy chains of I $\alpha \mathbf{l}$, facilitating covalent links of the latter to HA, whereas the addition of a monoclonal anti-TNFAIP6 antibody impeded COC expansion in rodents (Chen et al. 1996, Carrette et al. 2001, Fulop et al. 2003, Ochsner et al. 2003, Rugg et al. 2005, Sanggaard et al. 2005, Wisniewski et al. 2005). Interestingly, the present study indicates that the expression of equine TNFAIP6 coincides with the induction of HA synthase- 2 and the production of $\mathrm{HA}$, detected from $12 \mathrm{~h}$ after hCG in equine preovulatory follicles, as previously reported (Stock et al. 2002). Of interest, further studies will be needed to verify the presence of $|\alpha|$, and the co-localization of TNFAIP6, l $\alpha \mathbf{l}$, and HA in the equine preovulatory follicles, as observed in rodent ovaries (Carrette et al. 2001). As HA is present in equine preovulatory follicles, functional roles of TNFAIP6 through binding to HA are likely present in equine preovulatory follicles, including the inhibition of CD44 + leukocyte adhesion in COC expansion (Lesley et al. 2003, Wisniewski et al. 2005) and plasmin activity, and consequently inhibition of matrix metalloproteinases required to degrade ECM during ovulation as reported in rodents (Wisniewski et al. 1996). The present study indicates the expression of TNFAIP6 in theca and mural granulosa cells. Since the animal physiology and technical difficulties to isolate the COC from equine preovulatory follicles, the expression of TNFAIP6 in equine cumulus cells could not verify. However, as the latter expression in mural granulosa cells appear similar to that occurred in cumulus granulosa cells in rodents, we can suggest that a similar tendency may be observed in equine preovulatory follicles. As the expression of TNFAIP6 is predominant in theca layers, this suggests, in addition to cumulus expansion, other roles of TNFAIP6 in equine preovulatory follicles. For an example, at theca layers, TNFAIP6 may involve during the alteration of follicular basement membrane or in major vascular changes that highly occurred in this compartment during the ovulatory process (Kerban et al. 1999). In addition, theca layer may represent an important site to provide TNFAIP6, together with granulosa cells, required for a successful expansion of COC.

Studies on the molecular control of TNFAIP6 induction are very limited. Previous reports have shown that the transactivation of TNFAIP6 promoter was stimulated by TNF- $\alpha$ interacting with the NF-IL6 cis-acting element 
(Klampfer et al. 1994), and the induction of TNFAIP6 mRNA was coincident with the increase in TNF- $\alpha$ concentration and COX-2 expression in gonadotropintreated immature rats (Rice et al. 1998, Yoshioka et al. 2000), suggesting the modulation of a marked increase in TNFAIP6 mRNA after hCG treatment by a transcription activation event. COX-2 and prostaglandin E2 (PGE2) receptor (EP2) are required for optimal expansion and ovulation (Davis et al. 1999, Hizaki et al. 1999, Matsumoto et al. 2001). Several studies have suggested the involvement of the COX-2/PGE2/EP2-signaling pathway in the gonadotropin-dependent simulation of TNFAIP6 in cumulus expansion of rodents, since mice lacking COX-2 or EP2 gene display altered TNFAIP6 mRNA and protein expression in cumulus cells, but not in mural granulosa cells (Ochsner et al. 2003). In addition, rats treated with indomethacin (a non specific COX inhibitor) exhibited a significant reduction of TNFAIP6 transcripts prior to ovulation (Yoshioka et al. 2000). Our study revealed the increase in levels of TNFAIP6 message in a biphasic pattern in both granulosa and theca cells of equine preovulatory follicles, but the precise reasons for this biphasic induction remain unknown. It is tempting to speculate that the initial increase of TNFAIP6 may result from the first instance of gonadotropin surge, such as the induction of TNF- $\alpha$, IL-1 $\beta$, and the accumulation of HA (detected from $12 \mathrm{~h}$ post-hCG; Stock et al. 2002), whereas the second increase coincided with the COX-2 induction (detected from $30 \mathrm{~h}$ post-hCG; Sirois \& Doré 1997, Boerboom \& Sirois 1998) may result from COX-2 activity, thereby supporting the role of prostaglandins in the increase of TNFAIP6.

Ovulation is a complex process that has been characterized as an acute inflammatory reaction (Espey 1980). Our results indicate that follicles collected prior to ovulation were by far the tissues that most highly expressed TNFAIP6 mRNA, differing from very low or undetectable levels observed in other non-ovarian tissues tested. This difference may be due to the fact that TNFAIP6 expression is an integral part of the cascade of inflammatory-like changes that occur in preovulatory follicles, while the latter expression is usually undetectable in normal tissues (Milner \& Day 2003).

Lastly, the present study describes for the first time the cloning and characterization of equine TNFAIP6. Its protein sequence is highly similar (90-93\%) to that of other species, and identical in length with human (Lee et al. 1992), three amino acids shorter than bovine (GenBank accession number: NM_001007813) and two amino acids longer than mouse (Fulop et al. 1997) homologs. More importantly, all putative structural and functional domains are conserved in equine TNFAIP6 protein, including the signal peptide of 19 amino acid residues (Lee et al. 1992), two asparagine $N$-glycosylation consensus sequences, one site for chondroitin sulfate linkage, one distinct structural domain, referred to as a Link module, responsible for HA binding, and one characteristic region, referred to as a CUB domain, whose function remains unclear (Goetinck et al. 1987, Perin et al. 1987).

In summary, this study reports the primary structure of equine TNFAIP6, its transcript induction, and the presence of its protein in equine follicles during the ovulatory process in vivo. In contrast to rodents, the induction of equine TNFAIP6 is prolonged and biphasic in granulosa and theca cells. This induction is coincident with the increase of HA production and vascular changes in preovulatory follicles (Kerban et al. 1999, Stock et al. 2002), suggesting that TNFAIP6 may involve in the equine ovulatory process, including alteration of follicular basement membrane, and COC stabilization and expansion. Further studies are needed to determine the precise molecular mechanism behind the gonadotropin-dependent regulation of TNFAIP6 and its functional roles involved in this important physiological process in mares. Considering its large size and a long ovulatory process, the equine preovulatory follicle provides a valuable model to elucidate these issues and to further study the ovarian function of TNFAIP6 in a monoovulatory species.

\section{Acknowledgements}

The authors would like to thank Danielle Rannou for her technical help with the immunohistochemistry and Drs Alan K Goff and Bruce Murphy for their review and constructive criticisms of the manuscript. Natural Sciences and Engineering Research Council of Canada Grant OPG0171135 (to J S) supported this work. The nucleotide sequence reported in this paper has been submitted to the GenBank/EBI Data Bank with accession number AY919871. The authors declare that there is no conflict of interest that would prejudice the impartiality of this scientific work.

\section{References}

Aitken RJ, Bowie H, Buckingham D, Harkiss D, Richardson DW \& West KM 1992 Sperm penetration into a hyaluronic acid polymer as a means of monitoring functional competence. Journal of Andrology 13 44-54.

Bayliss MT, Howat SL, Dudhia J, Murphy JM, Barry FP, Edwards JC \& Day AJ 2001 Up-regulation and differential expression of the hyaluronan-binding protein TSG-6 in cartilage and synovium in rheumatoid arthritis and osteoarthritis. Osteoarthritis and Cartilage 9 $42-48$.

Boerboom D \& Sirois J 1998 Molecular characterization of equine prostaglandin $\mathrm{G} / \mathrm{H}$ synthase-2 and regulation of its messenger ribonucleic acid in preovulatory follicles. Endocrinology 139 1662-1670.

Boerboom D, Kerban M \& Sirois J 1999 Dual regulation of promoter IIand promoter $1 \mathrm{f}$-derived cytochrome P450 aromatase transcripts in equine granulosa cells during human chorionic gonadotropininduced ovulation: a novel model for the study of aromatase promoter switching. Endocrinology 140 4133-4141.

Boerboom D, Pilon N, Behdjani R, Silversides DW \& Sirois J 2000 Expression and regulation of transcripts encoding two members of 
the NR5A nuclear receptor subfamily of orphan nuclear receptors, steroidogenic factor- 1 and NR5A2, in equine ovarian cells during the ovulatory process. Endocrinology 141 4647-4656.

Boerboom D, Russell DL, Richards JS \& Sirois J 2003 Regulation of transcripts encoding ADAMTS-1 (a disintegrin and metalloproteinase with thrombospodin-like motifs-1) and progesterone receptor by human chorionic gonadotropin in equine preovulatory follicles. Journal of Molecular Endocrinology 31 473-485.

Bork P \& Beckmann G 1993 The CUB domain. A widespread module in developmentally regulated proteins. Journal of Molecular Biology 231 539-545.

Bradford MM 1976 A rapid and sensitive method for the quantitation of microgram quantities of protein utilizing the principle of protein-dye binding. Analytical Biochemistry 72 248-254.

Brown KA, Boerboom D, Bouchard N, Dore M, Lussier JG \& Sirois J 2004 Human chorionic gonadotropin-dependent regulation of 17beta-hydroxysteroid dehydrogenase type 4 in preovulatory follicles and its potential role in follicular luteinization. Endocrinology 145 1906-1915.

Carrette O, Nemade RV, Day AJ, Brickner A \& Larsen W 2001 TSG-6 is concentrated in the extracellular matrix of mouse cumulus oocyte complexes hrough hyaluronan and inter-alpha-inhibitor binding. Biology of Reproduction 65 301-308.

Chen L, Mao SJ \& Larsen WJ 1992 Identification of a factor in fetal bovine serum that stabilizes the cumulus extracellular matrix. A role for a member of the inter-trypsin inhibitor family. Journal of Biological Chemistry 267 12380-12386.

Chen L, Zhang H, Powers RW, Russell PT \& Larsen WJ 1996 Covalent linkage between proteins of the inter- $\alpha$-inhibitor family and hyaluronic acid is mediated by a factor produced by granulosa cells. Journal of Biological Chemistry 271 19409-19414.

Davis BJ, Lennard DE, Lee CA, Tiano HF, Morham SG, Wetsel WC \& Langenbach R 1999 Anovulation in cyclooxygenase-2-deficient mice is restored by prostaglandin E2 and interleukin-1ß. Endocrinology 140 2685-2695.

Duchamp G, Bour B, Combarnous Y \& Palmer E 1987 Alternative solutions to hCG induction of ovulation in the mare. Journal of Reproduction and Fertility. Supplement 35 221-228.

Espey LL 1980 Ovulation as an inflammatory reaction - a hypothesis. Biology of Reproduction 22 73-106.

Fulop C, Kamath RV, Li Y, Otto JM, Salustri A, Olsen BR, Glant TT \& Hascall VC 1997 Coding sequence, exon-intron structure and chromosomal localization of murine TNF-stimulated gene 6 that is specifically expressed by expanding cumulus cell-oocyte complexes. Gene 202 95-102.

Fulop C, Szanto S, Mukhopadhyay D, Bardos T, Kamath RV, Rugg MS, Day AJ, Salustri A, Hascall VC, Glant TT \& Mikecz K 2003 Impaired cumulus mucification and female sterility in tumor necrosis factorinduced protein-6 deficient mice. Development 130 2253-2261.

Getting SJ, Mahoney DJ, Cao T, Rugg MS, Fries E, Milner CM, Perretti M \& Day AJ 2002 The link module from human TSG-6 inhibits neutrophil migration in a hyaluronan- and inter-inhibitorindependent manner. Journal of Biological Chemistry 277 51068-51076.

Ginther OJ 1992 Characteristics of the ovulatory season. In Reproductive biology of the mare. Cross Plaines, WI: Equiservices. pp 173-235.

Glant TT, Kamath RV, Bardos T, Gal I, Szanto S, Murad YM, Sandy JD, Mort JS, Roughley PJ \& Mikecz K 2002 Cartilage-specific constitutive expression of TSG-6 protein (product of tumor necrosis factor alpha-stimulated gene 6) provides a chondroprotective, but not antiinflammatory, effect in antigen-induced arthritis. Arthritis and Rheumatism 46 2207-2218.

Goetinck PF, Stirpe NS, Tsonis PA \& Carlone D 1987 The tandemly repeated sequences of cartilage link protein contain the sites for interaction with hyaluronic acid. Journal of Cell Biology 105 2403-2408.

Hizaki H, Segi E, Sugimoto Y, Hirose M, Saji T, Ushikubi F, Matsuoka T, Noda Y, Tanaka T, Yoshida N, Narumiya S \& Ichikawa A 1999
Abortive expansion of the cumulus and impaired fertility in mice lacking the prostaglandin $\mathrm{E}$ receptor subtype $\mathrm{EP}(2)$. PNAS 96 10501-10506.

Jessen TE \& Odum L 2003 Role of tumour necrosis factor stimulated gene 6 (TSG-6) in the coupling of inter-alpha-trypsin inhibitor to hyaluronan in human follicular fluid. Reproduction 125 27-31.

Kerban A, Doré M \& Sirois J 1999 Characterization of cellular and vascular changes in equine follicles during hCG-induced ovulation. Journal of Reproduction and Fertility 117 115-123.

Klampfer L, Lee TH, Hsu W, Vilcek J \& Chen-Kiang S 1994 NF-IL6 and AP- 1 cooperatively modulate the activation of the TSG- 6 gene by tumor necrosis factor alpha and interleukin-1. Molecular and Cellular Biology 14 6561-6569.

Lee TH, Wisniewski HG \& Vilcek J 1992 A novel secretory tumor necrosis factor-inducible protein (TSG-6) is a member of the family of hyaluronate binding proteins, closely related to the adhesion receptor CD44. Journal of Cell Biology 116 545-557.

Lesley J, English NM, Gal I, Mikecz K, Day AJ \& Hyman R 2002 Hyaluronan binding properties of a CD44 chimera containing the link module of TSG-6. Journal of Biological Chemistry 277 26600-26608.

Mahi-Brown CA \& Yanagimachi R 1983 Parameters influencing ovum pickup by oviductal fimbria in the golden hamster. Gamete Research 8 1- 10.

Matsumoto H, Ma W, Smalley W, Trzaskos J, Breyer RM \& Dey SK 2001 Diversification of cyclooxygenase-2-derived prostaglandins in ovulation and implantation. Biology of Reproduction 64 1557-1565.

Milner CM \& Day AJ 2003 TSG-6: a multifunctional protein associated with inflammation. Journal of Cell Science 116 1863-1873.

Mindrescu C, Dias AA, Olszewski RJ, Klein MJ, Reis LF \& Wisniewski HG 2002 Reduced susceptibility to collagen-induced arthritis in DBA/1J mice expressing the TSG-6 transgene. Arthritis and Rheumatism 46 2453-2464.

Mukhopadhyay D, Hascall VC, Day AJ, Salustri A \& Fulop C 2001 Two distinct populations of tumor necrosis factor-stimulated gene- 6 protein in the extracellular matrix of expanded mouse cumulus cell-oocyte complexes. Archives of Biochemistry and Biophysics 394 173-181.

Neuwinger J, Cooper TG, Knuth UA \& Nieschlag E 1991 Hyaluronic acid as a medium for human sperm migration tests. Human Reproduction 6 396-400.

Ochsner SA, Russell DL, Day AJ, Breyer RM, Gomer RH \& Richards JS 2003 Decreased expression of tumor necrosis factor-stimulated gene 6 in cumulus cells of the cyclooxygenase-2 and EP2 null mice. Endocrinology 144 1008-1019.

Perin JP, Bonnet F, Thurieau C \& Jolles P 1987 Link protein interactions with hyaluronate and proteoglycans. Characterization of two distinct domains in bovine cartilage link proteins. Journal of Biological Chemistry 262 13269-13272.

Rice VM, Limback SD, Roby KF \& Terranova PF 1998 Changes in circulating and ovarian concentartions of bioactive tumor necrosis factor alpha during the first ovulation at puberty and in gonadotropintreated immature rats. Journal of Reproduction and Fertility 113 337-341.

Rugg MS, Willis AC, Mukhopadhyay D, Hascall VC, Fries E, Fulop C, Milner CM \& Day AJ 2005 Characterization of complexes formed between TSG- 6 and inter- $\alpha$-inhibitor that act as intermediates in the covalent transfer of heavy chains onto hyaluronan. Journal of Biological Chemistry $28025674-25686$.

Russell DL, Doyle KMH, Ochsner SA, Sandy JD \& Richards JS 2003 a Processing and localization of ADAMTS- 1 and proteolytic cleavage of versican during cumulus matrix expansion and ovulation. Journal of Biological Chemistry 278 42330-42339.

Russell DL, Ochsner SA, Hsieh M, Mulders S \& Richards JS 2003b Hormone-regulated expression and localization of versican in the rodent ovary. Endocrinology 144 1020-1030. 
Salustri A, Camaioni A, Di Giacomo M, Fulop C \& Hascall VC 1999 Hyaluronan and proteoglycans in ovarian follicles. Human Reproduction Update 5 293-301.

Sanggaard KW, Karring H, Valnickova Z, Thogersen ID \& Enghild JJ 2005 The TSG- 6 and $|\alpha|$ interaction promotes a transesterification cleaving the protein-glycosaminoglycan-protein (PGP) cross-link. Journal of Biological Chemistry 280 11936-11942.

Sayasith K, Bouchard N, Sawadogo M, Lussier JG \& Sirois J 2004 Molecular characterization and role of bovine upstream stimulatory factor 1 and 2 in the regulation of the prostaglandin $\mathrm{G} / \mathrm{H}$ synthase- 2 promoter in granulosa cells. Journal of Biological Chemistry 279 6327-6336.

Sayasith K, Bouchard N, Boerboom D, Brown KA, Dore M \& Sirois J 2005 Molecular characterization of equine P-selectin (CD62P) and its regulation in ovarian follicles during the ovulatory process. Biology of Reproduction 72 736-744.

Sirois J \& Doré M 1997 The late induction of prostaglandin G/H synthase2 in equine preovulatory follicles supports its role as a determinant of the ovulatory process. Endocrinology 138 4427-4434.

Sirois J, Kimmich TL \& Fortune JE 1991 Steroidogenesis by equine preovulatory follicles: relative roles of theca interna and granulosa cells. Endocrinology 128 1159-1166.

Stabenfeldt GH, Hughes JP, Evans JW \& Geschwind II 1975 Unique aspects of the reproductive cycle of the mare. Journal of Reproduction and Fertility. Supplement 23 155-160.

Stock A, Bouchard N, Brown K, Spicer AP, Underhill CB, Dore M \& Sirois J 2002 Induction of hyaluronan synthase 2 by human chorionic gonadotropin in mural granulosa cells of equine preovulatory follicles. Endocrinology 143 4375-4384.

Szanto S, Bardos T, Gal I, Glant TT \& Mickecz K 2004 Enhanced neutrophil extravasation and rapid progression of proteoglycaninduced arthritis in TSG-6-knockout mice. Arthritis and Rheumatism $503012-3022$.
Wisniewski HG \& Vilcek J 2004 Cytokine-induced gene expression at the crossroads of innate immunity inflammation and fertility. TSG-6 and PTX3/TSG-14. Cytokine \& Growth Factor Reviews 15 129-146.

Wisniewski HG, Maier R, Lotz M, Lee S, Klampfer L, Lee TH \& Vilcek J 1993 TSG-6: a TNF-, IL-1-, and LPS-inducible secreted glycoprotein associated with arthritis. Journal of Immunology 151 6593-6601.

Wisniewski HG, Burgess WH, Oppenheim JD \& Vilcek J 1994 TSG-6, an arthritis-associated hyaluronan binding protein, forms a stable complex with the serum protein inter-alpha-inhibitor. Biochemistry 33 7423-7429.

Wisniewski HG, HA JC, Poppers DM, Naime D, Vilcek J \& Cronstein BN 1996 TNF/IL-1-inducible protein TSG-6 potentiates plasmin inhibition by inter-alpha-inhibitor and exerts a strong antiinflammatory effect in vivo. Journal of Immunology 156 1609-1615.

Wisniewski HG, Snitkin ES, Mindrescu C, Sweet MH \& Vilcek J 2005 TSG-6 protein binding to glycosaminoglycans: formation of stable complexes with hyaluronan and binding to chondroitin sulfates. Journal of Biological Chemistry 280 14476-14484.

Yoshioka S, Ochsner S, Russell DL, Ujioka T, Fujii S, Richards JS \& Espey LL 2000 Expression of tumor necrosis factor-stimulated gene-6 in the rat ovary in response to an ovulatory dose of gonadotropin. Endocrinology 141 4114-4119.

Zhuo L \& Kimata K 2001 Cumulus oophorus extracellular matrix: its construction and regulation. Cell Structure and Function $\mathbf{2 6}$ 189-196.

Received 27 March 2006

First decision 24 May 2006

Revised manuscript received 26 September 2006

Accepted 6 October 2006 